DOI http://dx.doi.org/10.18551/rjoas.2016-03.06

\title{
ORGANIZATION 2020 - AN EMPIRICAL STUDY OF THE CURRENT AND FUTURE IMPORTANCE OF ORGANIZATIONAL ISSUES FOR HORTICULTURAL COMPANIES AND THEIR PERCEIVED COMPETENCE IN GERMANY
}

\author{
Stephan G.H. Meyerding \\ Center for Business Management in Horticulture and Applied Research, \\ Gottfried Wilhelm Leibniz University Hanover, Hanover, Germany \\ E-mail: meyerding@zbg.uni-hannover.de
}

\begin{abstract}
Structural change, the increasing concentration of industry, and environmental issues are changing the competitive landscape in German horticulture. As in other fields of corporate management the priorities of organizational design are constantly changing. The aim of the present study is to identify issues which will characterize organizational design in the future from the perspective of decision-makers in German horticultural companies, to identify overarching trends and to capture the currently perceived competence of the decisionmakers in different fields, as well as their past experience. The study specifically aims to indicate issues where a gap between future importance and perceived competence is present. For this purpose more than 150 entrepreneurs and executives from horticulture participated in an online survey in 2014. Most participants in the study were from ornamental horticulture, tree nurseries and vegetable farms. The main finding was that soft issues such as employee-motivation/employee-engagement/empowerment and the design of corporateculture are approximately 50\% more often considered one of the five most important organizational issues in 2020 than hard issues such as general cost-reduction and restructuring. Moreover, there is a critical gap in the perceived competence in future issues such as the optimization-of-leadership-levels, and issues that are already of substantial importance, such as the design-of-corporate-culture and performance-management. A significant positive relationship was observed between self-evaluated economic-success and today's subjective importance of optimization-of-leadership-levels, innovation-management and project-management. According to the participating horticultural companies, there is a perceived need for action, especially in the soft subjects: organization-of-the-corporateculture, cross-divisional-collaboration/cooperation-behavior, leadership and processmanagement.
\end{abstract}

\section{KEY WORDS}

Organizational design, business development, economic sustainability, future issues, human resource management, change management.

Demographic change (Bundesministerium für Ernährung, 2012), environmental issues ${ }^{1}$ and the concentration of the industry (Dirksmeyer, 2009) are changing the competitive landscape in German horticulture - and they have dominated the agenda of the industry for many years. The focus is on environmental regulations and costs, and company-wide costcutting and restructuring. While some major issues for corporate success require a more long-term perspective (Bitsch, 1994; Kölbel 2012) - from leadership to employee satisfaction and motivation - many not be the first priority for many horticultural companies.

Horticulture companies in Germany have been increasing in their organizational size for decades (Dirksmeyer, 2009). This growth has led to an increasing need for professionalization in many areas of the company. The organization of the horticultural

\footnotetext{
${ }^{1}$ In a separate survey of horticultural entrepreneurs ( $\left.n=124\right)$ replied to the question "Which five "megatrends" will be the cause of fundamental change processes in your company in the next decade?" $63.7 \%$ said environment (e.g. climate change, requirements, costs). Environmental issues are thus the megatrend in German horticulture, outside the labor market (for example, "war-for-talent" shortage of skilled workers) with $39.5 \%$.
} 
company is also likely to change. Organizational design has the objective to optimize structures and processes.

The focus of organizational design is on strategy, structure and systems (Vahs (2007, p. 359). The organizational structure of a horticultural company could continue to differentiate in the course of growth and be characterized by increasing standardization and specialization. This raises questions about the present and future importance of certain organizational issues for horticultural companies, from the perspective of horticultural entrepreneurs and executives. The evaluation of the self-assessment of decision-makers with regard to the competence of their company in the respective organizational issues can be an indication of where future gaps between importance and their competence exist. As in other areas of business management, the focus is always changing in organizational design (Lechner and Hettich, 2014; Anderson and King, 1993; Battisti and Stoneman, 2005; Betcherman 1997), however, overarching trends can be identified.

This study attempts to answer the following questions in a broader perspective:

- What issues of organizational design are considered particularly important for the future (in 2020) by decision-makers in horticultural companies?

- Where are overriding trends seen - within the plurality of individual subjects?

- What are the competences of horticultural companies in different areas of organizational design?

- What measures have been carried out by horticultural companies in the respective areas of organizational design, in the last three years?

\section{MATERIALS AND METHODS}

The study is based on an online survey of more than 150 horticultural entrepreneurs and executives in Germany, which was supplemented by interviews with business consultants.

A total of 23 organizational issues were examined (see Figure 1), as identified in empirical studies as parent organizational issues (Krüger, 1994, pp. 13 ff.; Krüger and Bach, 2015, p. 24) and assessed by horticultural entrepreneurs and executives as to their current and future importance. The respondents were presented with issues and then chose those that applied to their company. Executives and entrepreneurs were also asked which issues they viewed as competences in their company. All questions allowed the respondent's own ideas and opinions to be provided. The technical terms used were partly English, and explained in the questionnaire for the participants, who were provided with practical examples. The spectrum of organizational issues analyzed in the study can be divided into "hard" and "soft" issues (Krüger, 1994, pp. 13 ff.; Krüger and Bach, 2015, p. 24; see Figure 1 ). The costs and benefits of appropriate measures for hard organizational issues can be more clearly quantified than those for soft issues. Thus among the hard issues, are issues of structure (cost reduction and restructuring, optimization of management levels as well as margins) and control (degree of centralization, corporate governance, decision-making), as well as the processes (process management, out/co-sourcing, innovation management). The soft issues include all issues related to employees, cooperation and transformation. Some of the issues are naturally both hard and soft, and include both components. This is particularly true for project management. To allow comparison of this study of the horticultural industry with other industries in Germany, the systematic, classification and selection of organizational issues were adopted from a study by the Boston Consulting Group (BCG) in collaboration with the Society for Organization (GFO), the Austrian Association of Organization and Management (ÖVO) and the Swiss Society for Organization and Management (SGO) (Roghé et al., 2009). 


\section{Hard issues}

\section{Structure}

- Effective organizational criteria for the organizational structure

- Effective matrix organization / multidimensional organization

$>$ Optimization of management levels and margins

Cost reduction / restructuring

\section{Control}

- Global organization / degree of centralization

$\checkmark$ Role of the headquarter / Corporate Governance

- Optimization of decision-making processes

Business transparency and analysis

- Individual responsibility / accountability

\section{Processes}

Process management

- Shared services

Out-/co-sourcing, offshoring

$>$ Innovation management
Soft issues

\author{
Employees \\ Leadership \\ > Performance management \\ - Employee motivation / employee \\ engagement / empowerment \\ - Organization of corporate culture
}

\section{Cooperation}

- Cross-divisional collaboration/ cooperative behavior

Information- and knowledge management

- Networks / virtual organization

\section{Transformation \\ - Change management/ implementation \\ Project management \\ - Organizational flexibility / ability to integrate acquisitions}

Figure 1 - Hard and soft organization issues Own illustration: Cf.: Dalton, Todor, Spendolini, Fielding, and Porter (1980), Krüger (1994, pp. 13 ff.), Cartwright and Cooper (1995), Gadenne and Sharma (2009), Roghé, et al. (2009), Krüger and Bach (2015, p. 24)

Horticultural entrepreneurs and executives were interviewed in the period from June until December 2014 via an online questionnaire on the topics listed in Figure 1. Socially desirable or self-justified motives should be avoided through the use of multiple choice answers. For example, participants were asked to select five subjects in which they perceive their company as very competent, and not asked separately about the degree of competence in each subject. Structural data on the number of employees and the number of seasonal workers was also collected, since it can be assumed that the size of the organization has an effect on the answers. This influence was examined for each question. Since the company's business situation has an impact on the importance of different organizational issues, the study participants were asked how economically successful their business is compared to direct competitors. Study participants were asked to participate in the online survey via a personalized letter (by mail or email).

The interviewees represent the broad diversity of horticulture: floriculture, $33.1 \%$; tree nurseries, 31.4\%; vegetable farms, 27.8\%; and fruticulture, $7.7 \%(\mathrm{~N}=169)$. Tree nurseries and vegetable farms are over-represented in the sample, and fruit growers are underrepresented. $^{2}$ The focus of the sample was on production horticulture, so service companies are not included. Of the surveyed companies $74.1 \%$ employed less than ten employees $(\mathrm{N}=166)$ and $62.3 \%$ below five seasonal workers $(\mathrm{N}=138)$; only five companies surveyed had more than 50 seasonal workers. The proportion of companies in the sample with more than ten employees is larger than in the population, where about $80 \%$ of the horticulture production companies have fewer than ten employees, but the Horticulture Census 2005 does not distinguish between seasonal workers and permanent employees (Statistisches Bundesamt, 2006, pp. 72-73). The horticultural companies in the present study reported an average operating income of about 750,000 euros $(N=83)$, which corresponds approximately to the average operating income of participating companies in

\footnotetext{
${ }^{2}$ Population: fruticulture $31.9 \%, 25.5 \%$ floriculture, vegetable farms $17.6 \%$, tree nurseries $9.8 \%$ and others $15.1 \%$. Cf.: Gurrath (2006, p. 1039)
} 
the farm comparison of the Centre for Business Management in Horticulture and Applied Research $(777,582 \text { Euro, } \mathrm{N}=837)^{3}$.

Of the respondents, $89.9 \%$ were owners, executive committee members, managing directors or factory managers; $0.8 \%$ were the directors of a company or senior heads of department; $7.6 \%$ were department heads and $0.8 \%$ were project managers $(\mathrm{N}=119)$. Most participants in the study $(89.1 \%, \mathrm{~N}=128)$ had worked more than ten years in the company.

\section{RESULTS AND DISCUSSION}

Comparison of the Current and Future Importance of Organizational Issues. The study shows the issues that are increasingly important for the future and how companies perceive their current competence in the different areas, from the perspective of horticultural entrepreneurs and executives. When asked what issues will be the five most important for their company in 2020, both hard and soft issues were mentioned (see Figure 2). There is one recognizable trend: soft issues were on average about $50 \%$ more often named than hard ones by respondents in the study, as the five most important issues of the future. If the classic hard issues such as cost reduction and process management are excluded, then soft issues are classified as particularly important for the future (2020) more than twice as often than hard issues (see Figure 2).

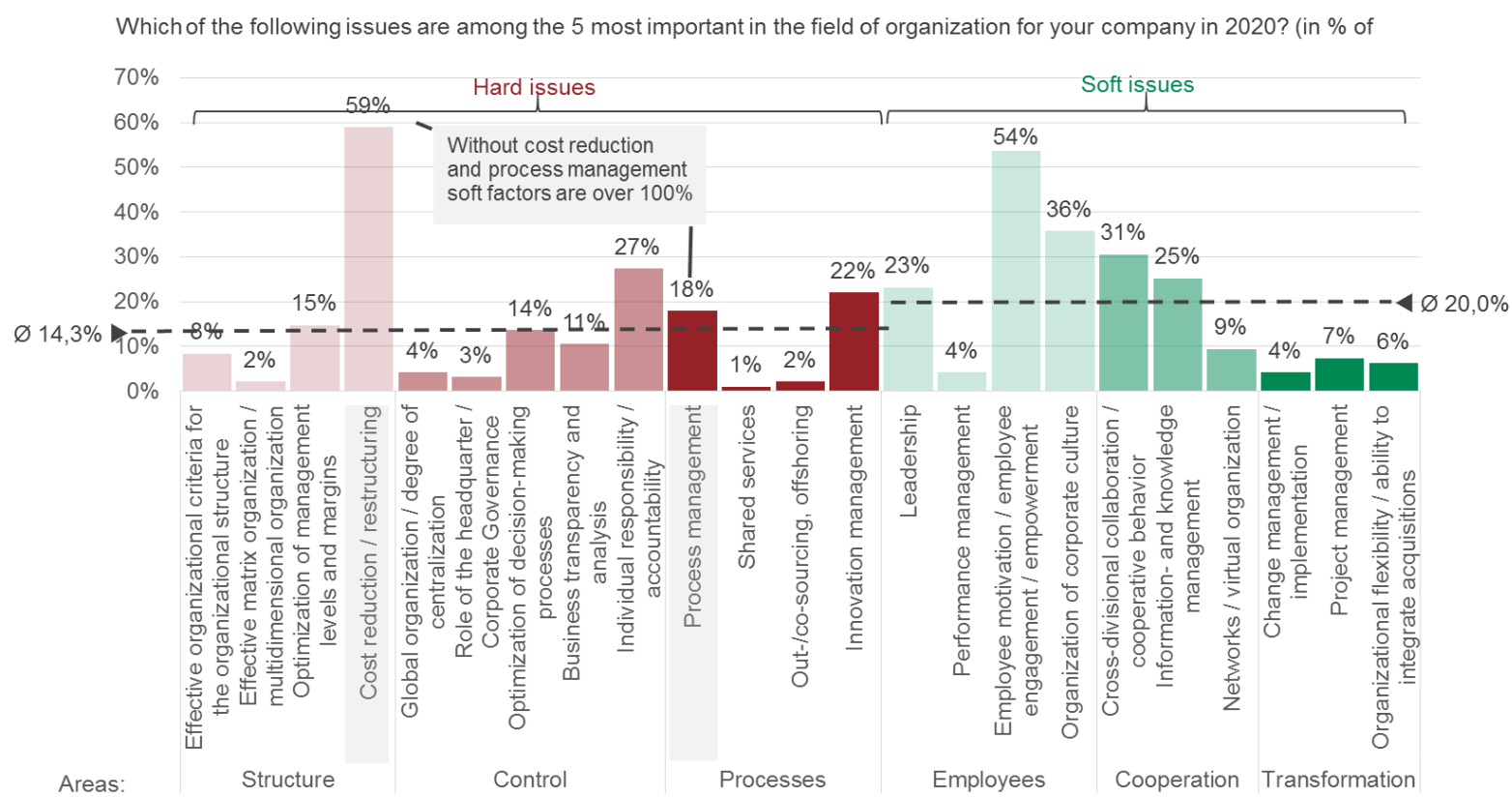

Figure 2 - Top issues for the future of organization in German horticulture - importance of soft factors (green)

As shown in Figure 1, the 23 organizational issues analyzed can be subdivided into six overarching areas. Most frequently organizational issues were named by the field employees of the five most important organizational issues in the future. After the area of personnel issues (employees) is the area organizational structure (structure), where the organization issue of cost reduction/restructuring is particularly important. In third, fourth and fifth place were areas of cooperation, control and processes. The area of transformation, including organizational issues change management/implementation, project management and organizational flexibility/ability to integrate acquisitions was least mentioned by respondents.

The area of employees (consisting of four organizational issues, see Figure 1) is rated as the most important area of future organizational design. Around half the respondents

\footnotetext{
${ }^{3}$ In the Horticultural Census 2005, operating income is not queried. Own calculation: floriculture, 823,559 euros, $n=472$; vegetable farms, 928,213 euros, $n=142$; tree nurseries, 550,112 euros, $n=38$ and fruticulture 591,381 euros, $n=185$; Cf.: Zentrum für Betriebswirtschaft im Gartenbau e. V. (2014, pp. 48-50)
} 
(53.7\%) expect that organizational management and the practical promotion of the organization issues employee motivation, employee engagement and empowerment (delegating responsibility and freedom of choice to the employees) within the company will be the main issues of organizational design in the future.

Change management, as a transformational organizational issue, is surprisingly of minor importance. Perhaps this is attributable to the term used in the survey and/or a lack of acceptance and presence of change management in horticulture, although the term was also noted as synonymous with 'organizational change' and explained in several places in the questionnaire.

The employee-oriented aspects of organizational design only follow after the major cost and structural issues (cost reduction/restructuring, 58.9\%). After employee motivation/employee engagement/empowerment (53.7\%) $35 \%$ of respondents noted the organization of corporate culture as an important issue for the future. Slightly fewer $(30.5 \%)$ expect that issues such as cross-divisional collaboration/cooperative behavior and leadership $(23.2 \%)$ will develop further in the coming years.

Relationships between different other variables were also examined. Since the multiple responses produced dichotomous variables, Kendall's tau-b $\left(\tau_{b}\right)$ correlation coefficient was used (Field, 2009, pp. 181-182). The significance level ( $p$ ) and the number of records used for the calculation $(n)$ is also indicated in the text. The structure and number of employees is also noted here, as these have an impact on the choice of topics. The complexity of the performance creation process also has an impact on the importance of various organizational issues. This has not been investigated in the present study.

German horticulture production companies, which employ many seasonal workers, noted individual responsibilities/accountability less frequently among the five most important organizational issues today $\left(\tau_{b}=-.19 ; p<0.05 ; n=138\right)$. The same applies to employee motivation/employee engagement/empowerment ( $\left.\tau_{\mathrm{b}}=-.22 ; \mathrm{p}<0.01 ; \mathrm{n}=138\right)$ and crossdivisional collaboration/cooperative behavior $\left(\tau_{b}=-.19 ; \mathrm{p}<0.05 ; \mathrm{n}=138\right)$. The current importance of project management $\left(\tau_{b}=.16 ; p<0.05 ; n=138\right)$ increases with the number of seasonal workers.

Horticultural companies with many seasonal workers note the issue of global organization/degree of centralization more frequently as a major organizational issue in the future (2020) than their counterparts with fewer seasonal workers $\left(\tau_{b}=.18 ; p<0.05 ; n=138\right)$, whereas they named issues such as leadership $\left(\tau_{b}=-.17 ; p<0.05 ; n=138\right)$, cross-divisional collaboration/cooperative behavior $\left(\tau_{b}=-.17 ; p<0.05 ; n=138\right)$ and network/virtual organization $\left(\tau_{b}=-.16 ; p<0.05 ; n=138\right)$ significantly less frequently as among the most important organizational issues in 2020 . Here the relative exchangeability of seasonal workers and the high degree of standardization in their tasks becomes visible. The complexity of the work increases the coordination and management effort needed, and therefore this is relatively low for seasonal workers.

Figure 3 compares the importance of organizational issues today and in 2020. The increase in importance is illustrated in the middle of figure 3 . This results from the difference between the percentage of respondents who described an issue as important for their business in 2020 and the percentage who considered the topic as important today. Based on the survey results, it is shown that - considering the current dominant priorities of organizational design - cost pressure remain significant, and the need for increasing business transparency and analysis is an important field, but soft issues are also gaining more in importance. It can be concluded that the current hotspots such as employee motivation/employee engagement/empowerment, organizational flexibility/integration of acquisitions and information and knowledge management should become standards in organizations.

The absolute percentage of responses about each organization issue is presented for today and 2020 on the right side in Figure 3. At this point it becomes clear that, for example, the issue of optimizing management levels as well as margins, shows the highest increase in importance $(10.3 \%)$, but that this increase is at an overall low level. Thus today $4.4 \%$ of 
respondents include this topic as the most important for their business, whereas the figure is $14.7 \%$ for 2020 , regarding the most important organizational issues.

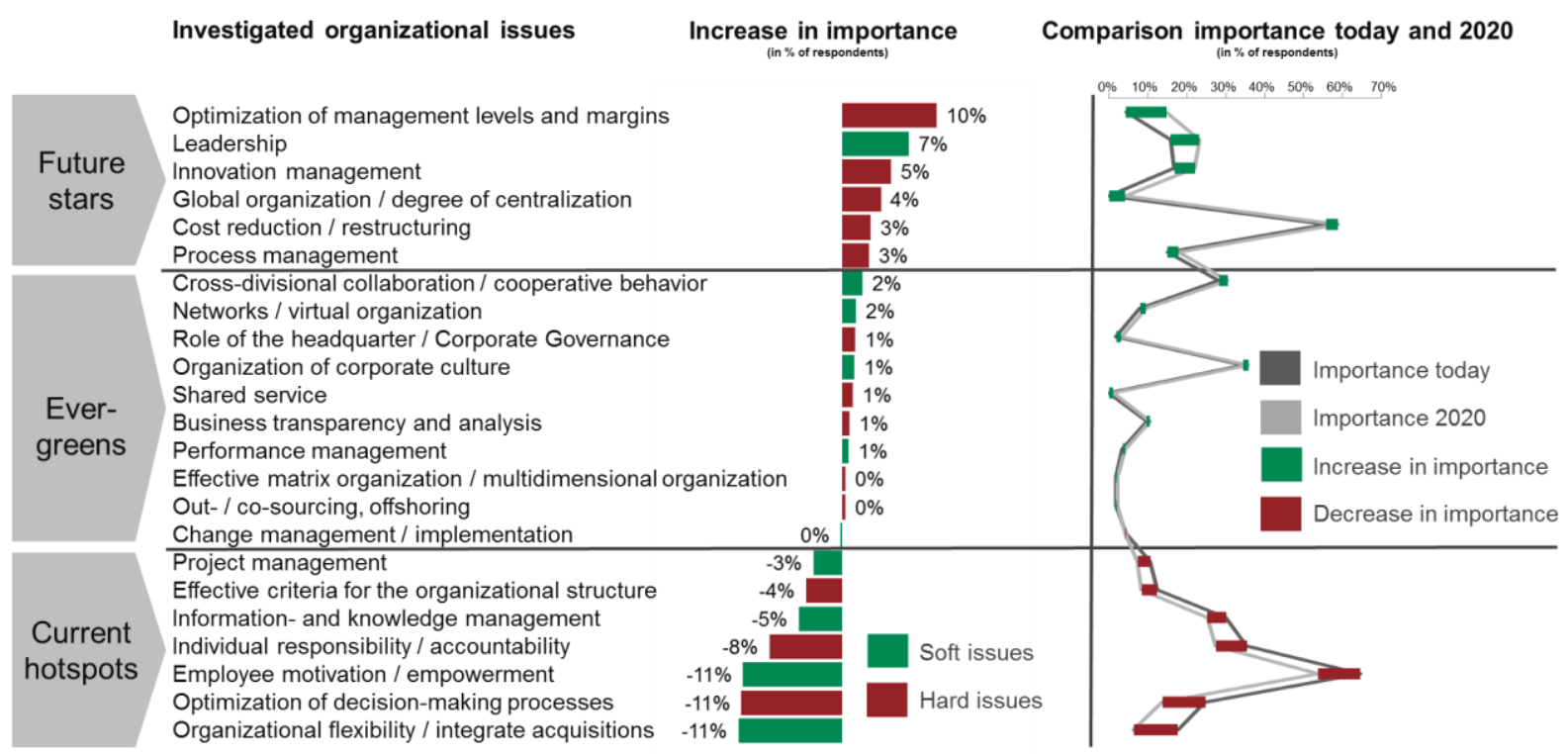

Figure 3 - The six most important issues in the field of organization today and 2020

Efficient decision-making processes and competitive cost structures are expected to be mandatory - even beyond current hotspots. Issues such as the optimization of management levels, as well as margins, innovation management, process management and leadership are the future stars of the surveyed horticultural entrepreneurs and executives. The increase in importance of these issues, comparing today and 2020, is pronounced most clearly.

Unchanged on the agenda are a series of issues which are considered relevant today and in the future. These include the design of corporate culture and the cross-divisional collaboration/cooperative behavior. The organization issues that represent current hotspots today will need to be solved from the perspective of decision-makers in order to continue succeeding on the market in the future.

Perceived Competence of Decision-makers with Respect to the Examined Organization Issues. In the next question, respondents were asked to select five organizational issues where they perceive their company as very competent. Overall, many executives perceive their companies less competent in hard than in soft issues.

With regard to the hard issues, capabilities in the field individual responsibilities/accountability (25.6\%) were assessed as particularly good. Almost every third person considers their company as particularly competent in the area cost reduction and restructuring (25.6\%). Similar proportions can be observed for optimizing decision-making processes $(22.1 \%)$ and innovation management $(24.4 \%)$. The issues of business transparency and analysis (17.4\%) and process management (14.0\%) were awarded almost average values. Horticultural entrepreneurs perceive their companies as less competent on issues such as effective organization criteria for the organizational structure $(7.0 \%)$, optimization of management levels as well as margins (5.8\%) and global organization/degree of centralization (2.3\%). In areas found more often in larger organizational units, as they can be found in horticulture as effective matrix organization/multidimensional organization, role of headquarter/corporate governance, shared services and out/co-sourcing/offshoring almost none of the companies surveyed perceived themselves as particularly competent. These topics are, however, considered of little relevance both today and in the future.

With regard to the soft issues, respondents feel especially competent regarding employee motivation/employee engagement/empowerment: almost $35 \%$ of respondents perceived their businesses as particularly competent in this area - a significantly higher proportion than for all other issues. This result is in contrast to statements in interviews with 
business consultants, where this issue alone was often described as having great potential for development. Project management, in $9.3 \%$ of respondents perceives themselves as being particularly competent, was assigned as a soft issue in the analysis, however, it also has major hard components, such as project planning and project controlling. In the field of transformation skills, just over a tenth of the horticultural entrepreneurs and executives see their own company as especially competent in terms of organizational flexibility/ability to integrate acquisitions (10.5\%); and even fewer in project management (9.3\%) and change management/implementation skills (4.7\%).

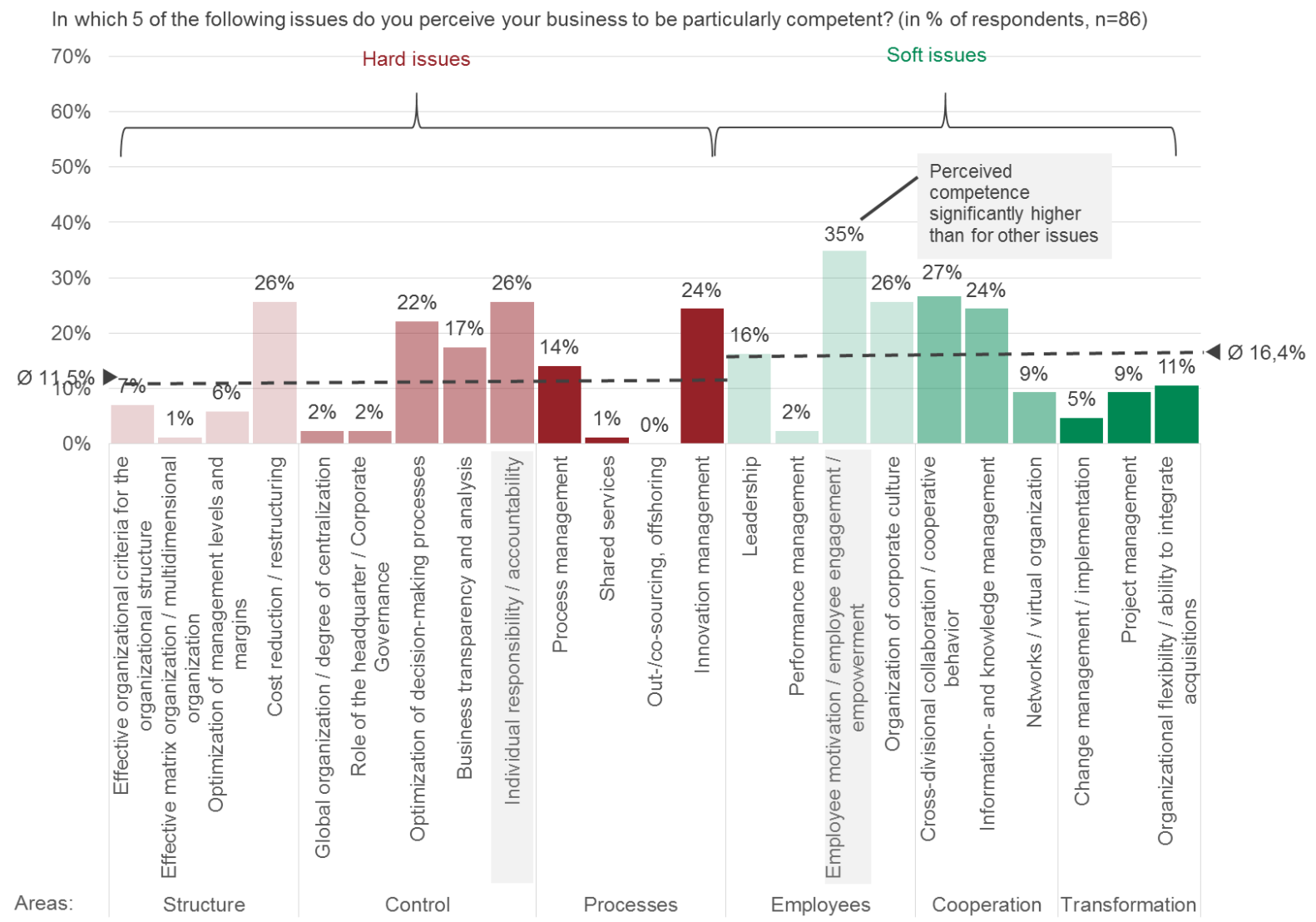

Figure 4 - Perceived competence of the entrepreneurs with respect to the 23 selected organizational issues

As less problematic among the soft issues applies information and knowledge management (24.4\%), which is positive because great importance is attached to this issue today (today $30.1 \% ; 25.3 \%$ in the future); even if the information and knowledge management will lose some of its relevance in the future from the perspective of the horticultural entrepreneurs.

Companies with many employees (excluding seasonal workers) often feel especially competent in the issue of optimizing management levels and margins $\left(\tau_{b}=.18 ; p<0.05\right.$; $\mathrm{n}=166)$, whereas the design of the corporate culture $\left(\tau_{b}=-.17 ; p<0.05 ; n=166\right)$ was significantly less frequently named among the five core competencies in organization, as in the case of their counterparts with fewer employees.

Comparison of Current and Future Importance and the Perceived Competence. Apart from the expected weighting of hard and soft issues in the future, the results of the survey suggest that there is a gap in many horticultural companies between their own competence and the relevance of issues. This gap indicates that action is needed (see Figure 5). 
Questions: "What are the 5 most important issues in the field of organization in your company today?", "Which of the following issues are among the 5 most important in the field of organization for your company in 2020 ?" and "For which 5 of the following issues would you perceive your business to be particularly competent?" (Source: Own survey)

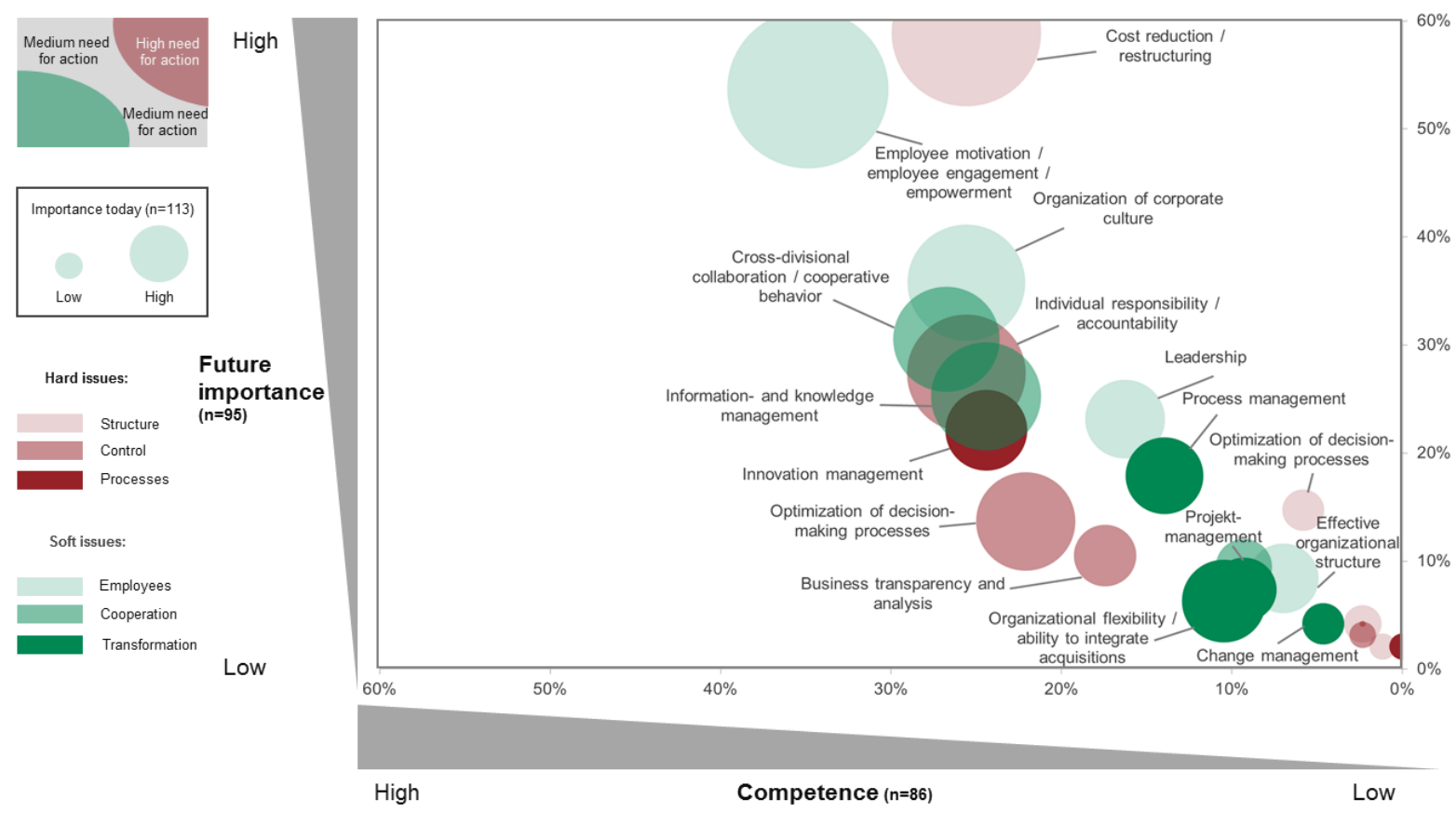

Figure 5 - Comparison of current and future importance and the perceived competence with respect to the 23 organization issues

Apart from cost reduction/restructuring and individual responsibilities/accountability there is only a small need for action on hard issues in the companies. The picture is different for the soft issues: with respect to the soft issues process management, leadership, crossdivisional collaboration/cooperative behavior and design of the corporate culture, the situation is critical, since perceived competence and the assessment of future importance are not pronounced to the same extent.

In addition to the importance of individual organizational issues the survey also includes other subjects, including how economically successful the horticultural companies judge themselves in comparison with their direct competitors (Likert scale from $1=$ not at all successfully; $5=$ very successful). If the self-assessment with regard to competency in organization issues is analyzed using perceived economic success compared to that of their direct competitors, then no significant relationship can be shown. A different picture emerges when comparing perceived economic success and the current subjective importance of organizational issues. Thus there is a significant positive relationship between subjective economic success and the current importance of optimizing management levels as well as margins $\left(\tau_{b}=.17 ; \mathrm{p}<0.05 ; \mathrm{n}=114\right)$ and a significant negative correlation with the current meaning of cost reduction/restructuring $\left(\tau_{b}=-.17 ; p<0.05 ; n=114\right)$. Another positive correlation was observed for today's importance of innovation management $\left(\tau_{b}=.15 ; p<0.05 ; n=114\right)$ and project management $\left(\tau_{b}=.15 ; p<0.05 ; n=114\right)$ and the current subjective economic success. There was also a significant relationship between the future importance of project management $\left(\tau_{b}=.17 ; p<0.05 ; n=114\right)$ and the present perceived economic success. Here horticulture is different from other industries. In the comparative study (Roghé, et al., 2009) the correlations with soft issues such as leadership, employee motivation, individual responsibilities, organization of corporate culture and change management were particularly high. Companies that perceived themselves as particularly competent in these aspects of their organization were subjectively economically more successful than others. In contrast, a low correlation between some classical subjects on the agenda of organizational design and the economic success of the company was shown: a minor influence on business success resulted - in contrast to the results in German horticulture - from the perceived competence in 
cost reduction/restructuring, role of headquarter/corporate governance and in out-/cosourcing and offshoring issues (Roghé, et al., 2009). It should not be concluded from this that the soft issues of organizational design in German horticulture would be more negligible than in other industries. It is more likely that the awareness and acceptance of soft organizational issues is not so pronounced in horticulture.

Measures in Practice. The experience with measures to increase competency in individual organizational aspects are showing in a similar direction in the comparative study (Roghé, et al., 2009): the results of measures in the field of soft issues were significantly more positively judged as such measures in the field of hard issues. Thus more than half the respondents said that they have had good experiences with measures to improve leadership skills, as well as with measures to promote employee motivation and to improve the crossdivisional cooperation in the comparative study. As Figure 6 shows, "hard" measures for cost reduction and restructuring $(71.9 \%$ of respondents) and only after that soft measures to motivate staff/employee engagement/empowerment (50.0\% of respondents) are mostly carried out in practice in German horticulture.

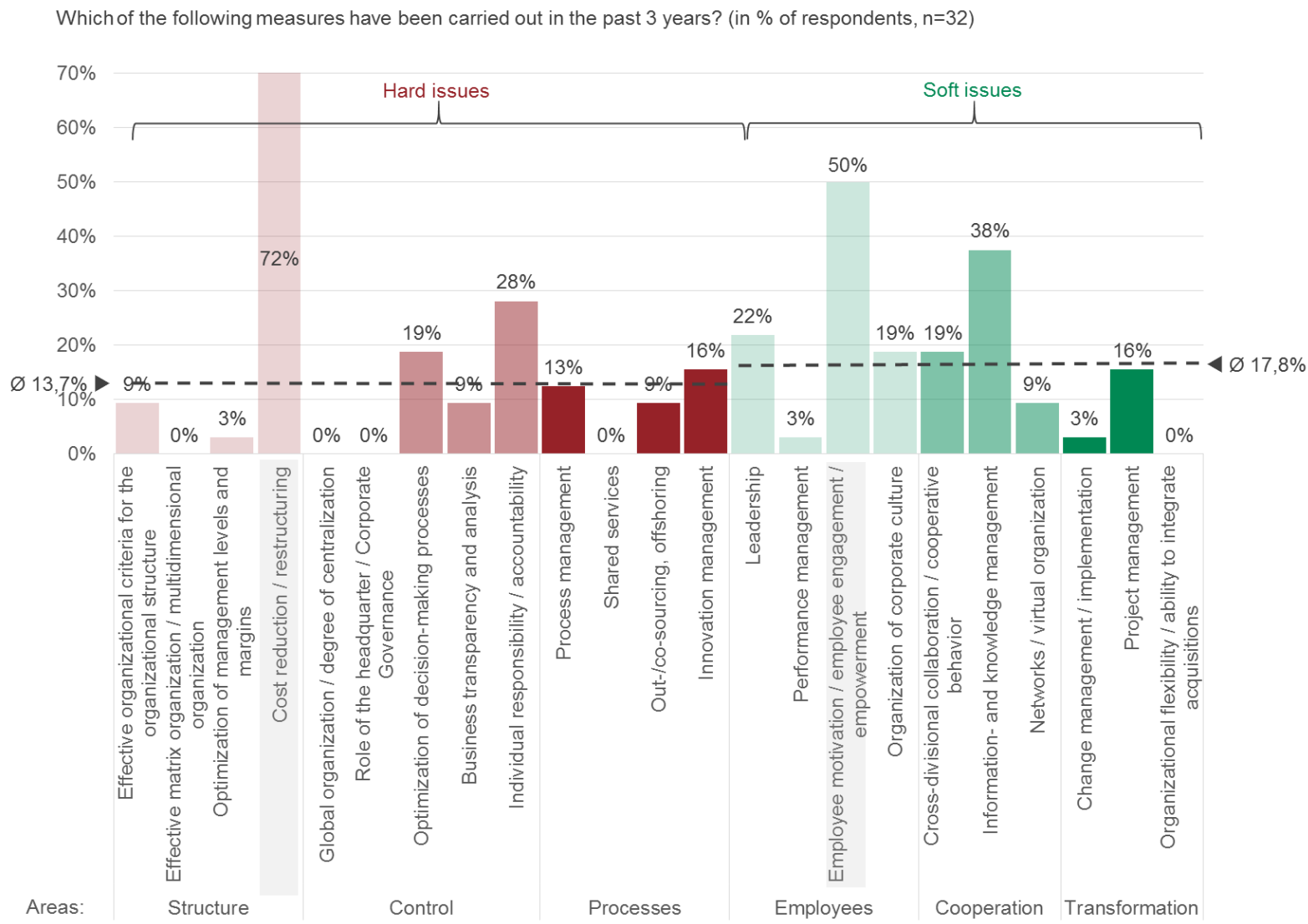

Figure 6 - Measures carried out in the last three years

After the top issues, cost reduction/restructuring and employee motivation/employee engagement/empowerment was the soft issue information and knowledge management, with $37.5 \%$ of respondents. The hard topic individual responsibility/accountability $28.1 \%$ and the issue leadership with $21.9 \%$ followed.

Overall, a surprisingly positive picture is shown in the frequency of measures on soft topics. This is also due to the fact that the hard thematic areas in which no measures have been carried out are more likely to come into question for larger organizations than for the respondent smaller horticultural companies. Included here are effective matrix organization/multidimensional organization, global organization/degree of centralization, the role of headquarters/corporate governance and shared services each with $0 \%$. Attention should also been paid to the results for the issue business transparency and analysis with 
9.4\%, in which the farm comparison of the Centre for Business and Management in Horticulture and Applied Research can be located. This may indicate that for many horticultural companies the benefit of such an analysis is not communicated clearly enough or is considered to be relatively low.

German horticulture production companies with many employees (excluding seasonal workers) have carried out more measures in the field of information and knowledge management in recent years, then their counterparts with fewer employees $\left(\tau_{b}=-.14 ; p<0.05\right.$; $\mathrm{n}=166$ ). Horticultural companies that perceive themselves as particularly economically successful compared to their direct competitors, have in the past three years more frequent performed measures towards process management $\left(\tau_{b}=.24 ; p<0.01 ; n=114\right)$ and innovation management $\left(\tau_{b}=.29 ; p<0.01 ; n=114\right)$.

Differences Between Horticulture and Other Industries in German-Speaking Countries. The results of this study can be compared with a comparative study (Roghé, et al., 2009) by the Boston Consulting Group (see Table 1). The comparative 2008 study is based on a survey of more than 1,000 executives and organization experts in Germany, Austria and Switzerland, which was supplemented by interviews with top managers. The respondents represented a wide variety of sectors: banking, insurance, service provider, automotive manufacturers, industrial goods manufacturing companies, technology and communications companies, retail, healthcare and pharmaceutical industry, energy, media, logistics, tourism and public administration. The average future importance of soft $(20 \%)$ and hard issues $(14 \%)$ is the same in the comparative study and the present study, however, there are significant differences within the superordinate areas. The hard issues cost reduction/restructuring (27\%), process management $(27 \%)$ and innovation management $(21 \%)$ are ranked most highly in the comparative study. In the sample of the present study, cost reduction/restructuring are even more important (58.9\%) and in second place are the individual responsibilities/accountability $(27.4 \%)$, followed by innovation management $(22.1 \%)$ and process management (17.9\%). With the increase of importance from today to 2020 many more soft issues are considered topics for the future in the comparative study, as in the sample of horticultural companies. In perceived competence, soft issues such as employee motivation/employee engagement/empowerment (34.9\%) and the cross-divisional collaboration/cooperation behavior $(26.7 \%)$ occupy the top places among horticultural companies. In the comparative study, perceived competence in project management (46\%) is significantly higher than all other subjects.

Table 1: Comparison of the results with those of the comparative study ${ }^{4}$

\begin{tabular}{|c|c|c|}
\hline Study & Present study & Comparative study \\
\hline Industry & Horticulture & Diverse industries \\
\hline Country & Germany & Germany, Austria, Switzerland \\
\hline \multirow{3}{*}{$\begin{array}{l}\text { Top } 3 \text { issues of the } \\
\text { future } \\
\text { (in \% of respondents) }\end{array}$} & $59 \%$ Cost reduction / restructuring & $27 \%$ Cost reduction / restructuring \\
\hline & $\begin{array}{l}\text { 54\% Employee motivation / employee } \\
\text { engagement / empowerment }\end{array}$ & $27 \%$ Process management \\
\hline & $36 \%$ Organization of corporate culture & $\begin{array}{l}26 \% \text { Change management / } \\
\text { implementation }\end{array}$ \\
\hline $\begin{array}{l}\text { Top } 3 \text { increase in } \\
\text { importance }\end{array}$ & $\begin{array}{l}10 \% \text { Optimization of management levels } \\
\text { and margins }\end{array}$ & $8 \%$ Innovation management \\
\hline \multirow[t]{2}{*}{ (in $\%$ of respondents) } & 7\% Leadership & $6 \%$ Networks / virtual organization \\
\hline & $5 \%$ Innovation management & $\begin{array}{l}6 \% \text { Information- and knowledge } \\
\text { management }\end{array}$ \\
\hline \multirow{3}{*}{$\begin{array}{l}\text { Top } 3 \text { perceived } \\
\text { competence } \\
\text { (in \% of respondents) }\end{array}$} & $\begin{array}{l}35 \% \text { Employee motivation / employee } \\
\text { engagement / empowerment }\end{array}$ & $46 \%$ Project management \\
\hline & $\begin{array}{l}27 \% \text { Cross-divisional collaboration / } \\
\text { cooperative behavior }\end{array}$ & $32 \%$ Process management \\
\hline & $\begin{array}{l}26 \% \text { Cost reduction / restructuring \& } \\
\text { individual responsibility / accountability } \\
\& \text { organization of corporate culture }\end{array}$ & $\begin{array}{l}31 \% \text { Cross-divisional collaboration / } \\
\text { cooperative behavior }\end{array}$ \\
\hline
\end{tabular}

\footnotetext{
${ }^{4}$ Own illustration. The results in the right column are from Roghé, et al. (2009)
} 
The top issues in terms of competence in horticultural companies are only in the average range in the comparative study. In the comparative study a similar need for action is shown when perceived competence and future importance are compared. An important exception is change management and its implementation, which is a subject in the comparative study where special action is required. Another major difference marks the issue individual responsibilities/accountability; on this issue almost no action is reflected in the comparative study, whereas it belongs to the hot spots for horticultural companies in the present study. The need for action on issues such as the role of headquarters/corporate governance, shared services, out/co-sourcing/offshoring and even business transparency and analysis can be evaluated as low in both studies, although in the comparative study, large companies in particular were surveyed, and their focus should accepted as more strongly on the mentioned topics.

\section{CONCLUSION AND OUTLOOK}

Overall, the survey results suggest that a competency assessment based on the 23 organizational issues considered can reflect the situation of an organization, although with varying relevance for individual issues depending on company-specific factors. This can be seen in that study participants rarely suggested their own issues (with the exception of termination of the business). The study shows a comprehensive picture of the current and future importance of different organizational issues and the perceived competence found in German production horticulture. Limitations arise from the number of participants $(\mathrm{N}=159)$, so that the study can not claim to be representative. The overall result of the study shows that, from the perspective of managers and horticulture entrepreneurs, there is a need for action in many areas - this is especially true for soft issues in the field of organizational design, such as the design of the corporate culture, cross-divisional collaboration/cooperative behavior, leadership and process management. This result is gaining weight, as implemented measures on cost reduction and restructuring in the last three years in the field of hard organizational issues with $71.9 \%$ still have the highest distribution. Cost reduction/restructuring and employee motivation/employee engagement/empowerment with $58.9 \%$ and $53.7 \%$, will be ranked most highly in 2020 , followed by the design of the corporate culture $(35.8 \%)$. The importance of the fields of optimization of management levels and margins, leadership, innovation management, global organization/degree of centralization, cost reduction/restructuring and process management will particularly increase. The horticulture companies perceive themselves as particularly competent in employee motivation/employee engagement/empowerment, however, this contradicts the reports of the expert interviews with business consultants.

The present study has demonstrated organizational issues where, from the perspective of corporate practices, action is needed in German horticulture production companies. This need for action should lead to change processes in the structural and procedural organization of horticultural companies. These change processes are themselves major challenges for companies. This leads to the question of how these change projects can be successfully performed. A change management study for horticulture will analyze the success factors of change processes as well as the current situation in German horticulture. The results of this study have underlined the particular relevance of the area of employees. The factors that have a significant impact on employee satisfaction in German horticulture are shown in an employee satisfaction study of the Centre for Business Management in Horticulture and Applied Research (Meyerding, 2015a; Meyerding, 2015b).

\section{ACKNOWLEDGEMENTS}

Thanks to Wolfgang Lentz for supporting the preparation of this paper. 


\section{REFERENCES}

1. Anderson, N. and King, N. (1993). Innovation in organizations. International Review of Industrial and Organizational Psychology 8: 1-34.

2. Battisti, G. and Stoneman, P. (2005). The intra-firm diffusion of new process technologies. International Journal of Industrial Organization 23: 1-22.

3. Betcherman, G. (1997). Organizational change and its implications for employment and human resource development: an overview paper: International conference organised jointly by the Ministry for Employment and Solidarity, France, and the OECD, at the Château de la Muette, Paris, 11 and 12 December 1997. Paris.

4. Bitsch, V. (1994). Erfolgsanalyse bei Gartenbaubetrieben auf der Basis von Jahresabschlußdaten (Diss.). Wilhelm Gottfried Leibniz Universität Hannover, Hannover.

5. Bundesministerium für Ernährung, L. u. V. (2012). Ergebnisdokumentation des Workshops "Rahmenbedingungen": 18.-19. September 2012 in Großbeeren. Berlin.

6. Cartwright, S. and Cooper, C. L. (1995). Organizational marriage: "hard" versus "soft" issues? Personnel Review 24: 32-42.

7. Dalton, D. R., Todor, W. D., Spendolini, M. J., Fielding, G. J. and Porter, L. W. (1980). Organization Structure and Performance: A Critical Review. Academy of Management Review 5: 49-64.

8. Dirksmeyer, W. (Ed.). (2009). Status quo und Perspektiven des deutschen Productionsgartenbaus. Braunschweig, Germany: Johann Heinrich von Thünen-Institut, Bundesforschungsinstitut für Ländliche Räume, Wald und Fischerei.

9. Field, A. P. (2009). Discovering statistics using SPSS: (and sex and drugs and rock ' $n$ ' roll) (3rd ed.). Introducing statistical methods. Los Angeles [i.e. Thousand Oaks, Calif.], London: Sage Publications.

10. Gadenne, D. and Sharma, B. (2009). An investigation of the hard and soft quality management factors of Australian SMEs and their association with firm performance. International Journal of Quality \& Reliability Management 26: 865-880.

11. Gurrath, P. (2006). Ergebnisse der Gartenbauerhebung 2005 (Wirtschaft und Statistik No. 10/2006). Wiesbaden.

12. Kölbel, C. (2012). Ein ökonomisches Betriebsmodell für den Produktionsgartenbau. Möglichkeiten der Modellierung mit Jahresabschlussdaten (Diss.). Gottfried Wilhelm Leibniz Universität Hannover, Hannover.

13. Krüger, W. (1994). Organisation der Unternehmung (3rd ed.). KohlhammerLehrbuchreihe Betriebswirtschaft. Stuttgart, Berlin, Köln: Kohlhammer.

14. Krüger, W. and Bach, N. (2015). Excellence in Change: Wege zur strategischen Erneuerung (5th ed.). Uniscope. Publikationen der SGO Stiftung. Wiesbaden: Gabler Verlag.

15. Lechner, C. and Hettich, E. (2014). Metaorganisationen. Zeitschrift Führung + Organisation 5: 333-339.

16. Meyerding, S. (2015a). Mitarbeiterzufriedenheit als Kernindikator sozialer Nachhaltigkeit. In W. Dirksmeyer, L. Theuvsen, \& M. Kayser (Eds.), Thünen Report 22. Aktuelle Forschung in der Gartenbauökonomie; Tagungsband zum 1. Symposium für Ökonomie im Gartenbau. am 27. November 2013 in der Paulinerkirche Göttingen (pp. 231-250). Braunschweig: Johann Heinrich von Thünen-Institut,.

17. Meyerding, S. G. H. (2015b). Job characteristics and job satisfaction: A test of Warr's vitamin model in German horticulture. The Psychologist-Manager Journal, 18: 86-107.

18. Roghé, F., Strack, R., Petrova, V., Grün, O., Krüger, W. and Sulzberger, M. (2009). Organisation 2015. ZFO - Zeitschrift Führung und Organisation 05: 201-208.

19. Statistisches Bundesamt. (2006). Land und Forstwirtschaft, Fischerei: Gartenbauerhebung 2005 (Fachserie 3). Wiesbaden.

20. Vahs, D. (2007). Organisation: Einführung in die Organisationstheorie und -praxis (6th ed.). Stuttgart: Schäffer-Poeschel.

21. Zentrum für Betriebswirtschaft im Gartenbau e. V. (2014). Kennzahlen für den Betriebsvergleich im Gartenbau 2014 (57. Jahrgang). Hannover. 